\title{
Prognostic factors in postoperative radiotherapy for prostate cancer - tertiary center experience
}

\author{
Marcin Miszczyk ${ }^{1}$, Wojciech Majewski², Konrad Stawiski ${ }^{3}$, Konrad Rasławski ${ }^{1}$, Paweł Rajwa ${ }^{4}$, \\ Iwona Jabłońska ${ }^{1}$, Łukasz Magrowski ${ }^{1}$, Oliwia Masri ${ }^{1}$, Andrzej Paradysz ${ }^{4}$, Leszek Miszczyk² \\ ${ }^{1} 3^{\text {rd }}$ Radiotherapy and Chemotherapy Department, Maria Sklodowska-Curie National Research Institute of Oncology, Gliwice, \\ Poland \\ ${ }^{2}$ Radiotherapy Department, Maria Sklodowska-Curie National Research Institute of Oncology, Gliwice, Poland \\ ${ }^{3}$ Department of Biostatistics and Translational Medicine, Medical University of Łodź, Łódź, Poland \\ ${ }^{4}$ Department of Urology, Medical University of Silesia, Zabrze, Poland
}

Radiol Oncol 2021; 55(2): 203-211.

Received 20 November 2020

Accepted 6 February 2021

Correspondence to: Marcin Miszczyk, $3^{\text {rd }}$ Radiotherapy and Chemotherapy Department, Maria Sklodowska-Curie National Research Institute of Oncology, ul. Wybrzeże Armii Krajowej 15, 44-102, Gliwice, Poland. E-mail: marcinmmiszczyk@gmail.com

Disclosure: No potential conflicts of interest were disclosed.

Background. The aim of the study was to analyse the prognostic factors in postoperative prostate cancer irradiation and develop a nomogram for disease-free survival (DFS).

Patients and methods. This retrospective study included 236 consecutive prostate cancer patients who had radical prostatectomy followed by radiotherapy (RT) at a single tertiary institution between 2009 and 2014. The main outcome was DFS analysed through uni- and multivariable analysis, Kaplan-Meier curves, log-rank testing, recursive partitioning analysis, and nomogram development.

Results. The median follow up was 62.3 (interquartile range [IQR] 38.1-79) months. The independent clinical factors associated with increased risk of recurrence or progression in the multivariate analysis (MVA) were prostate-specific antigen (PSA) level before RT, PT3 characteristic, and local failure as salvage indication. The value of PSA nadir had a significant impact on the risk of biochemical failure. Biochemical control and DFS were significantly different depending on treatment indication $(p<0.0001$ ). The recursive partitioning analysis highlighted the importance of the PSA level before RT, Gleason Grade Group, PSA nadir, and local failure as a treatment indication. Finally, the nomogram for DFS was developed and is available online at https://apps.konsta.com.pl/app/prostate-salvage-dfs/.

Conclusions. The Pre-RT PSA level, pT3 characteristic and local failure as salvage indication are pivotal prognostic factors associated with increased risk of recurrence or progression. The Gleason grade group of 4-5 and PSA nadir value allow for further risk stratification. The treatment outcomes in postoperative prostate cancer irradiation are significantly different depending on treatment indication. An online nomogram comprising of both pre-treatment and current data was developed allowing for visualization of changes in prognosis depending on clinical data.

Key words: prostate cancer; prognostic factors; postoperative radiotherapy; nomogram; disease-free survival

\section{Introduction}

The incidence of prostate cancer ( $\mathrm{PCa}$ ) has been steadily rising over the last decades. For example, The Polish National Cancer Registry has recorded a 28-fold increase in newly diagnosed Prostate Cancer patients, from 582 in 1963, through 2273 in
1990, up to 16253 newly diagnosed PCa patients in the year 2017.1,2 The change is directly associated with broad implementation of prostate-specific antigen (PSA) testing and aging society, but from a clinician's point of view, it means ever more patients to take care of. Despite changing patterns of PCa management, radical prostatectomy (RP) remains 
one of the pivotal treatment modalities in localized prostate cancer management, and so remains the necessity for management of post-prostatectomy treatment failures which occur in approximately $1 / 4^{\text {th }}$ of the patients, including up to $1 / 2^{\text {nd }}$ of those presenting high and very high risk group features. ${ }^{3}$

Historically, the necessity for further treatment was most commonly met by adjuvant radiotherapy (aRT), whose rationale was based on three large randomized clinical trials - SWOG S87944, EORTC 229115, and ARO 96-02/AUO AP 09/95. ${ }^{6}$ Although consistent in conclusions, these studies compared aRT with an outdated concept of salvage radiotherapy (sRT). The salvage treatment in the waitand-see groups was initiated significantly later than currently accepted standards, at the median PSA of 1.0 and $1.7 \mu \mathrm{g} / \mathrm{ml}$ for SWOG and EORTC studies respectively. Shortly after, authors started publishing reports on the superiority of early sRT initiation, which was later discussed along with the results of the ARO/AUO trial. Currently, the adverse association between PSA level prior to sRT and treatment results is well documented ${ }^{7}$, and the introduction of salvage treatment even prior to reaching the criteria for biochemical recurrence (i.e. $>0.4 \mathrm{ng} / \mathrm{ml}$ as in European Association of Urology [EAU] guidelines ${ }^{8}$ ) is encouraged.

The shift of the paradigm came with the recent results of TROG 08.03/ANZUP RAVES , RADICALS-RT ${ }^{10}$, and GETUG-AFU 1711, three large multicentre prospective randomized clinical trials comparing aRT with sRT initiated at very low levels of PSA, prior to the usual threshold of $>0.4 \mathrm{ng} / \mathrm{ml}$ for biochemical recurrence (BCR). The results were in favor of early sRT, and indicated that routine use of aRT leads to overtreatment of PCa patients. Although the studies were met with critique, the consistent results of the planned systemic review and meta-analysis published by the ARTISTIC collaboration ${ }^{12}$ suggest that for now, at least until data on long-term outcomes is available, sRT should be offered to all patients that are able and willing to adhere to the early sRT routine.

In this article, we present data from a large oneinstitutional set of consecutive PCa patients treated during the transitional period between aRT and sRT, and a thorough analysis of the prognostic factors.

\section{Patients and methods}

The retrospective observational cohort study included a group of 236 consecutive prostate cancer patients at median age of 63.6 years (min. 40, max. 82), who underwent RP between 1993 and 2013, and were later irradiated with aRT or sRT at single tertiary high-volume institution between 2009 and 2014 to the prostatic bed (as defined by the local protocol, similar to TROG 0803 RAVES trial ${ }^{13}$ ) with a median dose of 70 Gy (62-76 Gy) in 2 Gy fractions 5 times a week, using IGRT in all cases. Pelvic lymph node irradiation was performed in $26 \%$ of the patients using a standard dose of $44 \mathrm{~Gy}$ in 22 fractions. The androgen deprivation therapy (ADT) was administered in $37.6 \%$ of the patients prior to RT. Approximately $25.8 \%$ of the patients were receiving $\mathrm{ADT}$ at 4 months, $21.2 \%$ at 14 months, $18.2 \%$ at 26 months, $14.8 \%$ at 38 months and $11.4 \%$ at 50 months after treatment respectively. The ADT was administered at primary doctors' discretion. The follow up (FU) was collected retrospectively, based on our institutional database. In patients with $\mathrm{FU}<36$ months a phone call was attempted twice to obtain information regarding current PSA, ADT uptake, late side effects of RT, and permission to access the patients' medical history wherever further control visits took place. Data regarding overall survival (OS) was obtained from the Polish National Cancer Registry.

The study group was divided into four subgroups depending on the treatment indication including positive surgical margins (R1) and $\geq$ pT3 characteristic (pT3) for aRT, and BCR and local failure (LF) for sRT. In the case of dual treatment indications (i.e. $\mathrm{R} 1+\mathrm{pT} 3$ or $\mathrm{BCR}+\mathrm{LF}$ ) patients were assigned to pT3 and LF groups respectively. In few cases where patients qualified for aRT due to pT3 characteristic have had barely detectable PSA level (> $0.2 \mathrm{ng} / \mathrm{ml}$ ) in a post-qualification repeated PSA test immediately before RT, such patients were still regarded as part of the aRT group. The measured endpoints for the study were OS, disease-free survival (DFS), and biochemical control (BC). The OS, DFS and BC were calculated from the last day of RT to the day of death for OS, clinical recurrence defined as the locoregional failure, distant metastasis or both for DFS, and biochemical recurrence defined as PSA $>0.2 \mathrm{ng} / \mathrm{ml}$ for BC. Remaining cases were censored using the date of last observation with appropriate data to exclude the occurrence of the respective endpoint.

\section{Univariable analysis \& recursive partitioning analysis}

The univariate analysis was performed by fitting the proportional subdistribution hazards regres- 
TABLE 1. Description of the study group

\begin{tabular}{|c|c|c|c|c|c|}
\hline & Whole group & \multicolumn{2}{|c|}{ aRT } & \multicolumn{2}{|c|}{ SRT } \\
\hline Number of cases & 236 & \multicolumn{2}{|c|}{113} & \multicolumn{2}{|c|}{123} \\
\hline Age* & $63.6(59.8-68.4)$ & \multicolumn{2}{|c|}{$62.3(58.8-65.9)$} & \multicolumn{2}{|c|}{$65.2(60.5-70.2)$} \\
\hline $\begin{array}{l}\text { Time from surgery to RT } \\
\text { (months)* }\end{array}$ & $6(3.3-25.8)$ & \multicolumn{2}{|c|}{$3.6(2.9-4.8)$} & \multicolumn{2}{|c|}{$24.1(7.3-48.3)$} \\
\hline Indication & $\mathrm{n} / \mathrm{a}$ & $\mathrm{R} 1^{1}$ & pT32 & $\mathrm{BCR}^{3}$ & $\mathrm{LF}^{4}$ \\
\hline Max PSA pre-op* (ng/ml) & $9.16(6.81-14.6)$ & $8.24(6.33-11.78)$ & $9.37(7.19-14.79)$ & $10.67(7.3-17)$ & $8.8(6.6-13.3)$ \\
\hline Max PSA post-op*5 (ng/ml) & $0.27(0.04-1.13)$ & $0.035(<0.008-0.071)$ & $0.027(<0.008-0.104)$ & $0.72(0.38-1.92)$ & $1.19(0.45-2.89)$ \\
\hline PSA before RT* (ng/ml) & $0.2(0.023-0.78)$ & $0.015(<0.008-0.055)$ & $0.017(<0.008-0.077)$ & $0.56(0.29-1.07)$ & $1.05(0.35-2.38)$ \\
\hline \multicolumn{6}{|c|}{ Gleason Grade Group (post-op): } \\
\hline 4 & $5.6 \%$ & $1.8 \%$ & $7 \%$ & $7.4 \%$ & $5.8 \%$ \\
\hline 5 & $5.2 \%$ & $3.6 \%$ & $10.5 \%$ & $4.4 \%$ & $1.9 \%$ \\
\hline \multicolumn{6}{|l|}{ TNM (post-op): } \\
\hline pT2a-c & $61.6 \%$ & $100 \%$ & $0 \%$ & $63.6 \%$ & $84.3 \%$ \\
\hline рт3а & $17.5 \%$ & $0 \%$ & $50.9 \%$ & $12.1 \%$ & $7.8 \%$ \\
\hline pT3b & $21 \%$ & $0 \%$ & $49.1 \%$ & $24.2 \%$ & $7.8 \%$ \\
\hline $\mathrm{pNI}$ & $5.8 \%$ & $1.8 \%$ & $16.4 \%$ & $1.5 \%$ & $4 \%$ \\
\hline ADT prior to RT & $37.6 \%$ & $16.4 \%$ & $43.9 \%$ & $42.6 \%$ & $46.3 \%$ \\
\hline RT dose^ & $70 / 71.5$ & 70 / 70.3 & 70 / 70.2 & 70 / 71.4 & $76 / 74.4$ \\
\hline
\end{tabular}

* = median (interquartile range); $\wedge=$ median/mean Gy; $A D T=$ androgen deprivation therapy; $\mathrm{BCR}^{3}=$ biochemical recurrence; $\mathrm{LF}^{4}=$ local failure; $\mathrm{pT} 3^{2}=\mathrm{pT} 3 \mathrm{a}$ or $\mathrm{pT} 3 \mathrm{~b}$; $\mathrm{R}^{1}=\mathrm{R} 1$ resection; $\mathrm{RT}=$ radiotherapy; ${ }^{1-4}=$ in case of multiple indications only one is indicated. The assumed priority is: $\mathrm{LF}>\mathrm{BCR}>\mathrm{PT} 3>\mathrm{R} 1$

sion model, thus including the competing risk of death from other causes. Subdistribution hazard ratios (HR) were provided with their 95\% confidence intervals $(95 \% \mathrm{CI})$. To maintain consistency and generalizability, every univariate model was adjusted to the time length between surgery and radiation treatment (as a covariate). All factors tested in univariate analysis were included in the multivariate analysis which was also adjusted to the time between surgery and RT.

As an addition to multivariate analysis, to find the subgroups of different survival risks and select the most important clinical features, recursive partitioning for censored responses was performed. This utilized the development of a survival tree for DFS based on adjusted log-rank statistics (ctree algorithm).

\section{Nomogram development}

To develop the predictive model utilizing the current PSA and ADT status cause-specific Cox proportional hazards regression model with time-varying covariates was developed. The current PSA value was simplified to a binary variable based on the definition of post-RP BCR. ${ }^{14}$ Internal validation of the model and, thus, assessment of overfitting was performed using the bootstrap method with 1000 repetitions. The model performance was assessed using Harrell's C-index, with a value of 1.0 indicating perfect model concordance. The developed model was visualized using a nomogram and was implemented in the online calculator. The whole analysis was done using $\mathrm{R}$ programming language. 


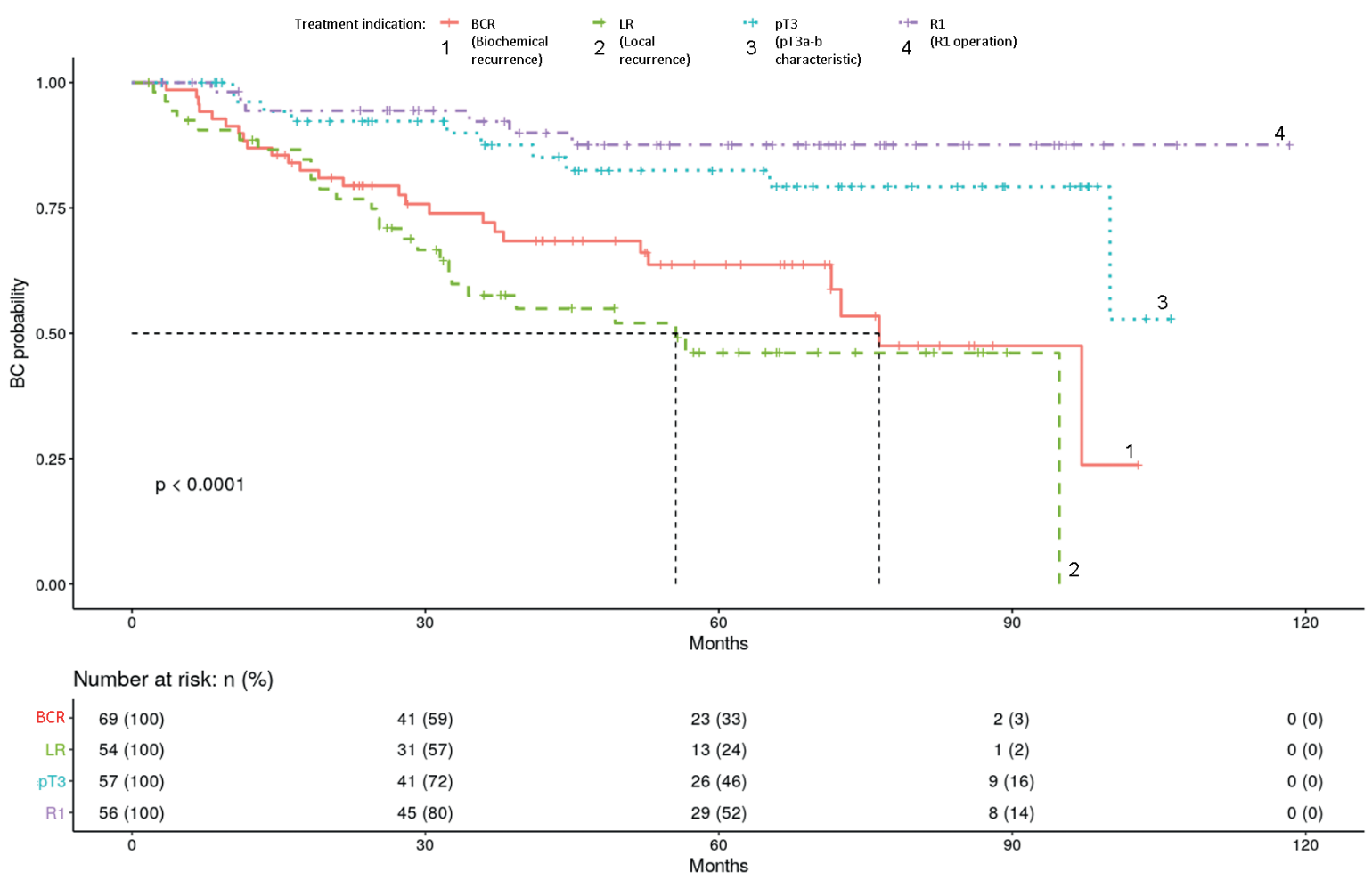

FIGURE 1. Biochemical control depending on treatment indication.

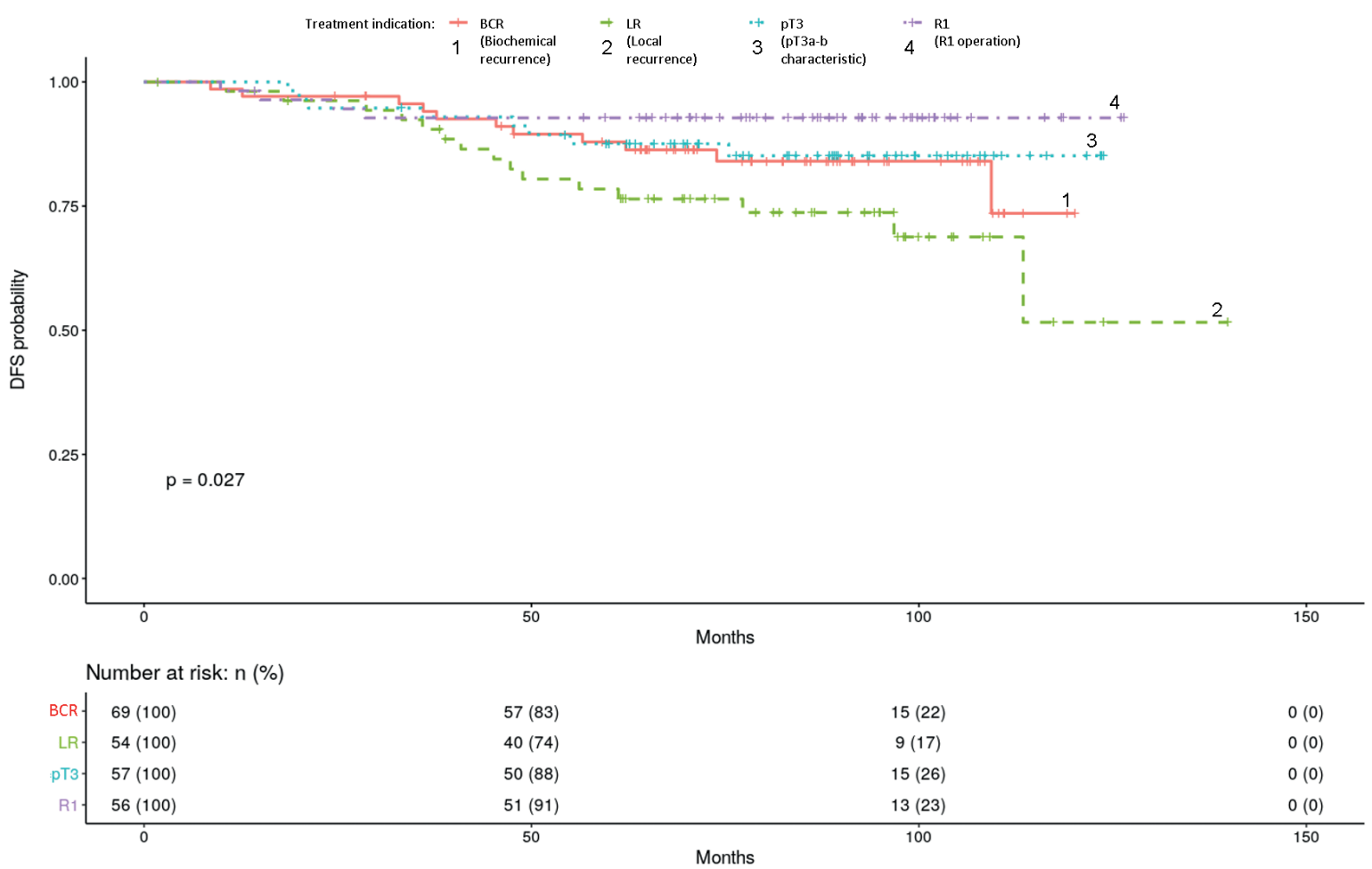

FIGURE 2. Disease-free survival (DFS) depending on treatment indication. 
TABLE 2. Univariate and multivariate analysis

\begin{tabular}{|c|c|c|c|c|c|c|c|c|}
\hline \multirow[b]{3}{*}{ Covariate: } & \multicolumn{4}{|c|}{ Univariate analysis } & \multicolumn{4}{|c|}{ Multivariate analysis } \\
\hline & \multicolumn{2}{|l|}{ DFS } & \multicolumn{2}{|l|}{ BC } & \multicolumn{2}{|l|}{ DFS } & \multicolumn{2}{|l|}{$\mathrm{BC}$} \\
\hline & $\mathrm{HR}(95 \% \mathrm{Cl})$ & p-value & HR (95\% CI) & $\mathrm{p}$-value & $\mathrm{HR}(95 \% \mathrm{Cl})$ & $p$-value & $\mathrm{HR}(95 \% \mathrm{Cl})$ & $\mathrm{p}$-value \\
\hline Age & $0.99(0.94,1.04)$ & 0.59 & $1.03(0.99,1.08)$ & 0.14 & $0.97(0.92,1.02)$ & 0.19 & $1.02(0.98,1.07)$ & 0.34 \\
\hline $\begin{array}{l}\text { max PSA prior to } \\
\text { operation }\end{array}$ & $1.03(0.97,1.08)$ & 0.35 & $1.03(1,1.07)$ & 0.078 & $1.04(0.97,1.11)$ & 0.25 & $1.05(1.02,1.08)$ & 0.001 \\
\hline $\begin{array}{l}\text { max PSA post } \\
\text { operation }\end{array}$ & $1(0.96,1.05)$ & 0.91 & $1.04(1.02,1.05)$ & $<.001$ & $0.53(0.28,1.01)$ & 0.052 & $1(0.99,1.02)$ & 0.65 \\
\hline $\begin{array}{l}\text { PSA before } \\
\text { radiotherapy }\end{array}$ & $1.24(1.12,1.37)$ & $<.001$ & $1.26(1.17,1.35)$ & $<.001$ & $2.17(1.04,4.55)$ & 0.04 & $1.19(1.03,1.38)$ & 0.017 \\
\hline ADT prior to RT & $1.42(0.74,2.74)$ & 0.29 & $1.06(0.64,1.75)$ & 0.82 & $1.39(0.69,2.77)$ & 0.35 & $0.82(0.5,1.35)$ & 0.43 \\
\hline pT3a-b vs. pT2a-c & $2.57(1.29,5.1)$ & 0.007 & $1.35(0.83,2.19)$ & 0.23 & $4.29(1.8,10.25)$ & 0.001 & $1.89(1.02,3.5)$ & 0.044 \\
\hline pNO vs pNl & $0.58(0.16,2.13)$ & 0.42 & $0.94(0.3,2.99)$ & 0.92 & $0.82(0.31,2.19)$ & 0.69 & $0.98(0.56,1.72)$ & 0.95 \\
\hline aRT indication - Rl & $0.6(0.27,1.31)$ & 0.2 & $0.36(0.2,0.64)$ & $<.001$ & $0.81(0.19,3.52)$ & 0.78 & $0.21(0.09,0.52)$ & 0.001 \\
\hline aRT indication - pT3a-b & $1.45(0.69,3.04)$ & 0.33 & $0.86(0.48,1.55)$ & 0.62 & $0.72(0.18,2.89)$ & 0.64 & $1.04(0.43,2.53)$ & 0.93 \\
\hline $\begin{array}{l}\text { SRT indication - } \\
\text { biochemical failure }\end{array}$ & $1.31(0.64,2.68)$ & 0.46 & $2.02(1.17,3.49)$ & 0.011 & $1.95(0.41,9.27)$ & 0.4 & $1.12(0.52,2.41)$ & 0.77 \\
\hline $\begin{array}{l}\text { SRT indication - local } \\
\text { failure }\end{array}$ & $2.03(1.06,3.89)$ & 0.033 & $2.36(1.45,3.84)$ & 0.001 & $2.39(1.11,5.15)$ & 0.026 & $1.48(0.77,2.83)$ & 0.24 \\
\hline $\begin{array}{l}\text { R1 operation } \\
\text { (regardless of RT } \\
\text { indication) }\end{array}$ & $1.2(0.61,2.35)$ & 0.59 & $0.82(0.5,1.32)$ & 0.41 & $1.52(0.59,3.92)$ & 0.38 & $2.17(1.23,3.84)$ & 0.007 \\
\hline PSA nadir (per lng/ml) & $1.34(1.2,1.5)$ & $<.001$ & $1.29(1.19,1.39)$ & $<.001$ & $1.16(0.93,1.46)$ & 0.19 & $1.37(1.28,1.46)$ & $<.001$ \\
\hline Gleason Grade Group & $1.4(1.09,1.8)$ & 0.009 & $1.15(0.96,1.38)$ & 0.12 & $1.28(0.95,1.73)$ & 0.1 & $1.13(0.93,1.38)$ & 0.23 \\
\hline
\end{tabular}

$\mathrm{ADT}=$ androgen deprivation therapy; $\mathrm{aRT}=\operatorname{adjuvant~} \mathrm{RT} ; \mathrm{RT}=$ radiotherapy; $\mathrm{SRT}$ = salvage $\mathrm{RT}$

\section{Results}

The median age of the patients at the onset of RT was 63.6 years (interquartile range [IQR] 59.8-68.4), median FU was 62.3 months (IQR 38.1-79) and $10.2 \%$ of the patients were found to be deceased at the time of data collection. The 5-year DFS and BC were $86.9 \%$ and $70 \%$ respectively. A detailed description of the patients' characteristics is presented in Table 1.

The uni- and multivariate (MVA) Cox Regression for the DFS found that among max PSA prior to operation, max PSA post operation and PSA immediately prior to RT, only the last one was a significant covariate and remained an independent adverse factor for the risk of clinical recurrence in the MVA (HR 2.17; $1.04-4.55 ; p=0.04)$. The pT3 characteristic was associated with significantly increased risk of developing clinical recurrence or progression in the MVA (HR 4.29; 1.8-10.25; $\mathrm{p}=0.001$ ) as well as local failure as a treatment indication (HR 2.39; 1.11-5.15; $p=0.026$ ). The PSA Nadir and Gleason Grade Group were both associated with an increased risk of DFS failure in the univariate analysis, but were no longer significant in the MVA. The
PSA Nadir, however, was associated with significantly increased risk of BCR in the MVA (HR 1.37; $1.28-1.46 ; p=0.001$ ) The HR's for the remaining covariates and results for BC can be found in Table 2 .

The probability of treatment failure differed between treatment indication. The differences were especially pronounced for $\mathrm{BC}$, and the log-rank testing resulted in a high level of statistical significance (Figure 1). The trend, however, was different for DFS (Figure 2). The difference in Kaplan-Meier curves between aRT due to PT3 characteristic and sRT due to BCR was very well pronounced in terms of $\mathrm{BC}$, but these two curves are similar for DFS.

The recursive partitioning analysis for DFS provided the decision tree presented in Figure 3. Out of all included clinical variables the final algorithm highlighted the importance of PSA before RT, postoperative GG, PSA nadir as well as a local failure as an indication for sRT creating 5 risk groups based on DFS. If the initial PSA level before RT exceeded $2.5 \mathrm{ng} / \mathrm{ml}$, this group was associated with the highest risk of relapse or progression. Postoperative GG was the second most important divider, with the score of GG 3 or lower separating the remaining patients into two further groups. The patients 


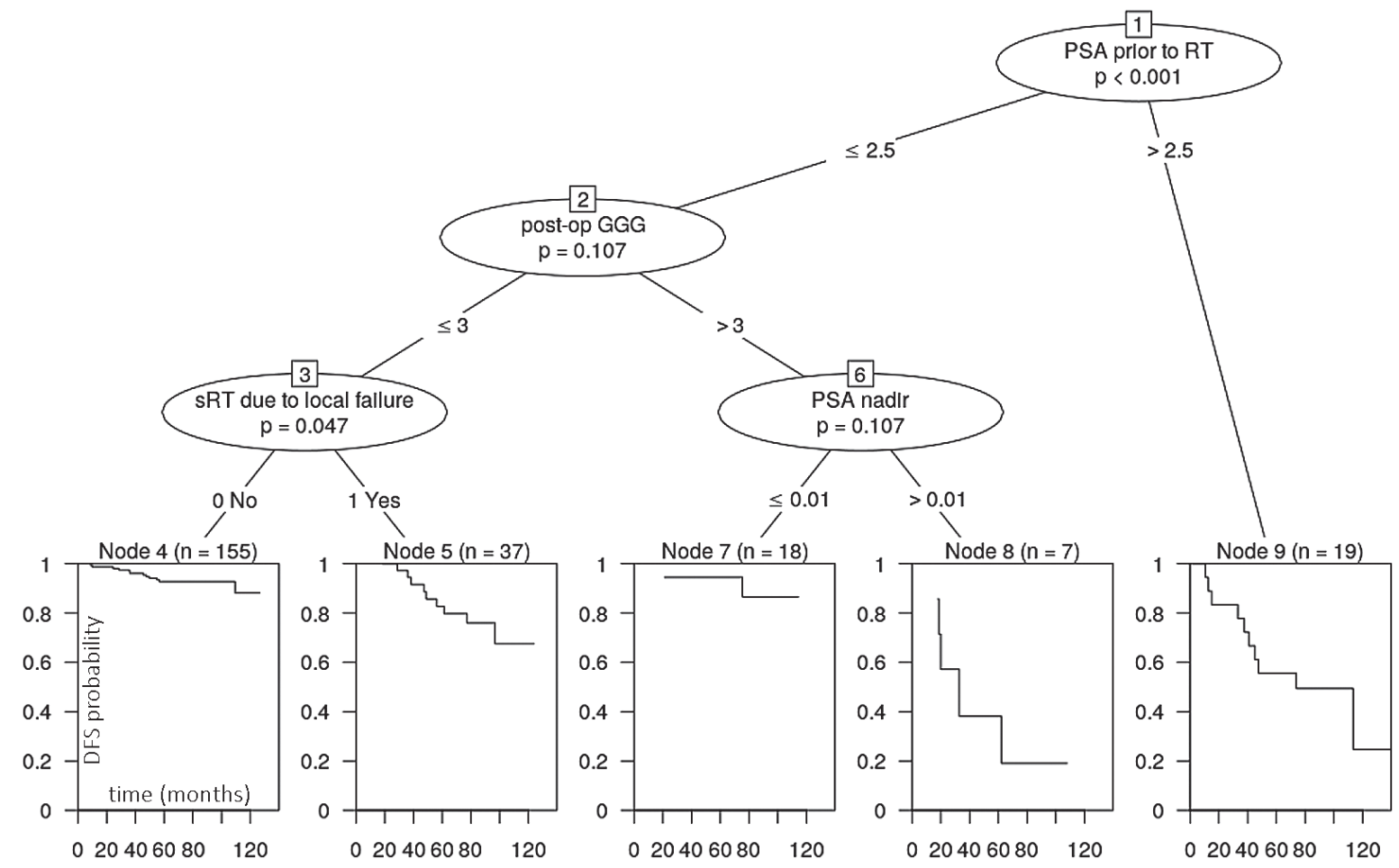

FIGURE 3. Recursive partitioning analysis for disease-free survival (DFS).

GGG = Gleason grade group; $\mathrm{SRT}$ = salvage $\mathrm{RT} ; \mathrm{RT}$ = radiotherapy

with GG of 4 or 5 were further divided by the value of PSA nadir. If the PSA ever reached values of $\leq$ 0.01 during Follow Up, the risk of DFS failure was lower. Finally, in patients with GG of 3 or lower, the patients treated with SRT due to LF had a significantly higher risk of relapse or progression.

Finally, the nomogram utilizing time-varying Cox regression model was developed and can be found in Figure 4. The c-index for this model was 0.81 (95\%CI: 0.73-0.89) which did not drop (i.e. remained 0.81 ) in a bootstrap-based validation, thus suggesting resilience to overfitting. This model was employed to create an online application, which visualises the impact of changing prognostic factors on the probability of clinical relapse or recurrence. The application is available online at https:// apps.konsta.com.pl/app/prostate-salvage-dfs/.

\section{Discussion}

There are many different available nomograms on the subject of prostate cancer treatment, the majority of those addressing the issue of risk stratification after primary radical prostatectomy, but the risk stratification in post-prostatectomy irradiation is significantly more difficult considering the heterogeneity of the patients and the recent changes in treatment recommendations. In this analysis, besides the commonly assessed pre-treatment variables comparable to those provided by the EAU for the post-RP distant metastasis recurrence ${ }^{15}$, we included ADT uptake and PSA levels as variables changing over time. Such approach allows for visualisation of changes in patients' prognosis over the course of the follow up, however, on the expense of reduced clinical importance of nomogram for initial risk evaluation.

There is evidence ${ }^{16}$ suggesting that distant metastases are a better intermediate clinical endpoint compared to BC. However, the use of distant metastasis as an endpoint in our article was limited due to the median length of FU (approximately 5 years). The BCR on average precedes clinical metastasis by 7 to 8 years ${ }^{17}$, and the actual risk of distant metastasis is underestimated. Therefore, we decided to use DFS and BC as surrogate endpoints, the latter universally preceding metastatic progression. ${ }^{8}$ Due to limited data, we have also omitted more thorough analysis of the ADT type and duration before RT, as in many cases the precise date of ADT onset was not available. A com- 


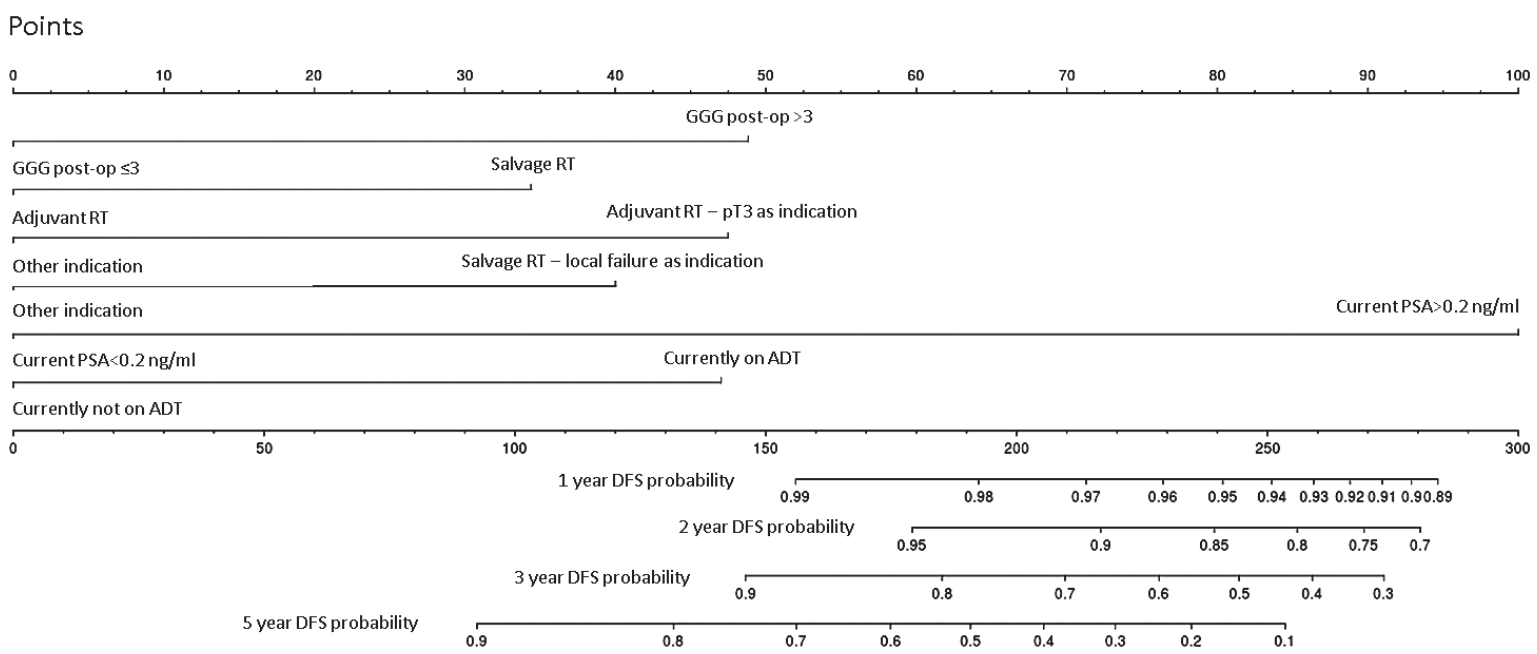

FIGURE 4. Nomogram for disease-free survival (DFS).

$\mathrm{ADT}=$ androgen deprivation therapy; GGG = Gleason grade group; $\mathrm{RT}$ = radiotherapy

mon flaw of retrospective studies on post-RT PCa patients is the lack of differentiation between aRT and sRT subpopulations. For example, a recent analysis by Hwang et al. in $2018^{18}$ concluded that aRT reduces $B C R$ and improves metastasis-free survival and OS in high-risk patients. The study was met with criticism regarding omitting patients who were cured by surgery alone. To account for such, we included the treatment indication as a co-factor in the statistical analysis and nomogram. Moreover, such criticism is advised in the interpretation of Kaplan-Meier curves presented in this article (Figure 1-2).

Tendulkar et al. ${ }^{7}$ published an excellent study which analyses the importance of pre-RT PSA levels and provides a nomogram for risk stratification of BCR and metastases-free survival in patients undergoing sRT. The analysis included a large study group $(n=2460)$ of node-negative patients with a detectable PSA post-RP. Notably, the nomogram includes one of the independent prognostic factors presented in our article, the pre-RT PSA level, as a continuous variable. Such approach allows for a conceptualization of the importance of early sRT initiation in case of post-RP BCR.

In another study, Dalela et al. ${ }^{19}$ created a prognostic nomogram including clinical features and Decipher (GenomeDx Biosciences, Inc., Vancouver, British Columbia) score for the identification of optimal candidates for aRT. Although the clinical importance of such a nomogram is limited in the sRT era, the study highlights the applicability of novel, genomic markers for the patients' risk stratification. Moreover, some authors suggest that a subset of patients presenting multiple and severe adverse prognostic factors, such as pT3b/pT4 feature and high Gleason Score which were also highlighted in this article, could profit from aRT despite the late findings. ${ }^{10-12,20}$

One of the important aspects of changing clinical practice is the introduction of new diagnostic methods. In this study, the majority of the DFS failures were diagnosed through medical imaging performed due to rising PSA $(24,63.2 \%)$, which was either fluorodeoxyglucose positron emission tomography (FDG-PET) (10 cases), prostate specific membrane antigen PET (PSMA-PET) (7 cases), bone scintigraphy (3 cases), computer tomography (CT) (2 cases) or magnetic resonance imaging (MRI) (2 cases). In 10 cases (26.3\%), at the time of $\mathrm{BCR}$, the localization of the recurrence could not be determined, and clinical recurrence was found later in routine imaging: MRI (5 cases), CT (2 cases), FDG-PET (1 case), PSMA-PET (1 case), or RTG ( 1 case). Finally, 4 patients had clinical progression diagnosed before $\mathrm{BCR}$, through bone scintigraphy (1 case), CT (1 case), MRI (1 case), or physical examination (1 case). The majority of these diagnostic tools could be replaced with broader usage of PSMA-PET in the future, as it seems to have superior sensitivity and specificity. ${ }^{21}$ The EAU guidelines ${ }^{8}$ suggest considering PSMA- PET in patients with persistent or recurrent PSA $(>0.2 \mathrm{ng} / \mathrm{ml})$ after RP. However, due to low evidence strength, accessibility, and relatively high cost compared to standard diagnostic methods, the implementation 
of routine PET-PSMA imaging is limited. Set aside logistic and economic factors, routine PET-PSMA could reduce the occurrence of treatment failures in the future through early diagnosis of occult distant metastasis and early implementation of modern techniques of localized treatment for oligometastatic disease. For example, despite limited prospective evidence, stereotactic RT has shown potential for long-term disease control in such patients based on our institutional experience. ${ }^{22,23}$

The TROG 08.03/ANZUP RAVES ${ }^{9}$, RADICALS$\mathrm{RT}^{10}$, and GETUG-AFU $17^{11}$ have recently shown that sRT approach is preferable to aRT for post-RP patients. However, the question remains whether it is possible to reproduce the clinical trial setting in practice. For example, In the RADICALS-RT trial $^{10}$, the median PSA value at the onset of sRT was $0.2 \mathrm{ng} / \mathrm{ml}(0.1-0.3)$, significantly lower than in our study group - $0.68 \mathrm{ng} / \mathrm{ml}$ (IQR 0.31-1.78). Considering that the PSA value before RT is an important prognostic factor ${ }^{7}$, which has been shown in our analysis, we can expect that the treatment outcomes of the second group of patients would be significantly worse. According to the pre-sRT PSA nomogram by Tendulkar et al. ${ }^{7}$, only $12(9.8 \%)$ patients had PSA $<0.2 \mathrm{ng} / \mathrm{ml}$ before RT, 38 (30.9\%) PSA $0.21-0.5 \mathrm{ng} / \mathrm{ml}, 29$ (23.5\%) PSA $0.51-1 \mathrm{ng} / \mathrm{ml}$, $17(13.8 \%)$ PSA $1.1-2 \mathrm{ng} / \mathrm{ml}$, and finally 25 (20.4\%) PSA $>2$. In 2 cases $(1.6 \%)$, the PSA pre-sRT value was missing. Increased frequency of PSA monitoring and early initiation of sRT could improve the treatment outcomes, however, it is often limited by patients' resources and compliance. Therefore, we believe that in patients with limited possibility of close follow-up and significant adverse prognostic factors, offering aRT could reduce the probability of a clinical recurrence.

We acknowledge the limitations and biases of a retrospective study. The study was based on single-institution data and limited follow-up, which could be further improved by the inclusion of other sites and registry-based collection of data, which we will try to accomplish in the future.

\section{References}

1. Kułakowski A, Zatoński W. Cancer in Poland in 1990. In: Zatoński W Tyczyński J, editos. Warsaw: Pracownia Poligraficzna Centrum Onkologii Instytutu im. Marii Skłodowskiej-Curie; 1990.

2. Didkowska J, Wojciechowska U, Czaderny K, Olasek P, Ciuba A. Cancer in Poland in 2017. Warsaw: Pracownia Poligraficzna Centrum Onkologii Instytutu im. Marii Skłodowskiej-Curie; 2017. [cited 2020 Feb 1]. Available at: http://onkologia.org.pl/wp-content/uploads/Nowotwory_2017.pdf
3. Park SW, Hwang DS, Song WH, Nam JK, Lee HJ, Chung MK. Conditional biochemical recurrence-free survival after radical prostatectomy in patients with high-risk prostate cancer. Prostate Int 2020; 8: 173-7. doi: 10.1016/j. prnil.2020.07.004

4. Thompson IM, Tangen CM, Paradelo J, Lucia MS, Miller G, Troyer D, et al Adjuvant radiotherapy for pathological T3NOMO prostate cancer significantly reduces risk of metastases and improves survival: long-term followup of a randomized clinical trial. J Urol 2009; 181: 956-62. doi: 10.1016/j. juro.2008.11.032

5. Bolla M, Van Poppel H, Tombal B, Vekemans K, Da Pozzo L, de Reijke TM, et al. Postoperative radiotherapy after radical prostatectomy for high-risk prostate cancer: long-term results of a randomised controlled trial (EORTC trial 22911). Lancet 2012; 380: 2018-27. doi: 10.1016/S0140-6736(12)61253-7

6. Wiegel T, Bartkowiak D, Bottke D, Bronner C, Steiner U, Siegmann A, et al Adjuvant radiotherapy versus wait-and-see after radical prostatectomy: 10-year follow-up of the ARO 96-02/AUO AP 09/95 trial. Eur Urol 2014; 66: 243-50. doi: 10.1016/j.eururo.2014.03.011

7. Tendulkar RD, Agrawal S, Gao T, Efstathiou JA, Pisansky TM, Michalski JM, et al. Contemporary update of a multi-institutional predictive nomogram for salvage radiotherapy after radical prostatectomy. J Clin Oncol 2016; 34: 3648-54. doi: 10.1200/JCO.2016.67.9647

8. Mottet N, Conford P, van den Bergh RCN, Briers E, De Santis M, Fantis S, et al. Prostate Cancer EAU Guidelines. Presented at the EAU Annual Congress Barcelona 2019. Arnhem, the Netherlands: EAU Guidelines Office; 2019. [cited 2020 Feb 1]. Available at: https://uroweb.org/guideline/prostatecancer/

9. Kneebone A, Fraser-Browne C, Delprado W, Duchesne G, Fisher R, Frydenberg $\mathrm{M}$, et al. A phase III multi-centre randomised trial comparing adjuvant versus early salvage radiotherapy following a radical prostatectomy: results of the TROG 08.03 and ANZUP "RAVES" trial. Int J Radiat Oncol 2019; 105: S37-8. doi: 10.1016/j.jijobp.2019.06.456

10. Parker CC, Clarke NW, Cook AD, Kynaston HG, Petersen PM, Catton C, et al. Timing of radiotherapy after radical prostatectomy (RADICALS-RT): a randomised, controlled phase 3 trial. Lancet 2020; 396: 1413-21. doi: 10.1016/ S0140-6736(20)31553-1

11. Sargos $P$, Chabaud $S$, Latorzeff I, Magné N, Benyoucef $A$, Supiot $S$, et al. Adjuvant radiotherapy versus early salvage radiotherapy plus short-term androgen deprivation therapy in men with localised prostate cancer after radical prostatectomy (GETUG-AFU 17): a randomised, phase 3 trial. Lancet Oncol 2020; 21: 1341-52. doi: 10.1016/S1470-2045(20)30454-X

12. Vale CL, Fisher D, Kneebone A, Parker C, Pearse M, Richaud P, et al. Adjuvant or early salvage radiotherapy for the treatment of localised and locally advanced prostate cancer: a prospectively planned systematic review and meta-analysis of aggregate data. Lancet 2020; 396: 1422-31. doi: 10.1016/ S0140-6736(20)31952-8

13. RAVES-Contouring Guidelines Revised July 2011. CTV Delineation. [cited 2020 Aug 15]. Available at: https://www.trog.com.au/SiteFiles/trogcomau/ TROG_0803_-_Guidelines_for_Contouring.pdf

14. Tourinho-Barbosa R, Srougi V, Nunes-Silva I, Baghdadi M, Rembeyo G, Eiffel SS, et al. Biochemical recurrence after radical prostatectomy: what does it mean? Int Braz J Urol 2018; 44: 14-21. doi: 10.1590/S1677-5538. IBJU.2016.0656

15. Van den Broeck T, van den Bergh RCN, Arfi N, Gross T, Moris L, Briers E, et al. Prognostic value of biochemical recurrence following treatment with curative intent for prostate cancer: a systematic review. Eur Urol 2019; 75: 967-87. doi: 10.1016/j.eururo.2018.10.011

16. Xie W, Regan MM, Buyse M, Halabi S, Kantoff PW, Sartor O, et al. Metastasisfree survival is a strong surrogate of overall survival in localized prostate cancer. J Clin Oncol 2017; 35: 3097-104. doi: 10.1200/JCO.2017.73.9987

17. Pound CR, Partin AW, Eisenberger MA, Chan DW, Pearson JD, Walsh PC. Natural history of progression after PSA elevation following radical prostatectomy. J Am Med Assoc 1999; 281: 1591-7. doi: 10.1001/ jama.281.17.1591

18. Hwang WL, Tendulkar RD, Niemierko A, Agrawal S, Stephans KL, Spratt DE, et al. Comparison between adjuvant and early-salvage postprostatectomy radiotherapy for prostate cancer with adverse pathological features. JAMA Oncol 2018; 4: e175230. doi: 10.1001/jamaoncol.2017.5230 
19. Dalela D, Santiago-Jiménez M, Yousefi K, Karnes RJ, Ross AE, Den RB, et al. Genomic classifier augments the role of pathological features in identifying optimal candidates for adjuvant radiation therapy in patients with prostate cancer: Development and internal validation of a multivariable prognostic model. J Clin Oncol 2017; 35: 1982-90. doi: 10.1200/JCO.2016.69.9918

20. Kneebone A, Fraser-Browne $C$, Duchesne GM, Fisher R, Frydenberg $M$, Herschtal A, et al. Adjuvant radiotherapy versus early salvage radiotherapy following radical prostatectomy (TROG 08.03/ANZUP RAVES): a randomised, controlled, phase 3, non-inferiority trial. Lancet Oncol 2020; 21: 1331-40. doi: 10.1016/S1470-2045(20)30456-3

21. Alipour R, Azad A, Hofman MS. Guiding management of therapy in prostate cancer: time to switch from conventional imaging to PSMA PET? Ther Adv Med Oncol 2019; 11: 1758835919876828. doi: 10.1177/1758835919876828

22. Napieralska A, Miszczyk L, Tukiendorf A, Stąpór-Fudzińska M. The results of treatment of prostate cancer bone metastases after CyberKnife radiosurgery. Ortop Traumatol Rehabil 2014; 16: 339-49. doi: 10.5604/15093492.1112535

23. Napieralska A, Miszczyk L, Stąpór-Fudzińska M. CyberKnife stereotactic ablative radiotherapy as an option of treatment for patients with prostate cancer having oligometastatic lymph nodes: single-center study outcome evaluation. Technol Cancer Res Treat 2016; 15: 661-73. doi: $10.1177 / 1533034615595945$ 